\title{
Primary Tumors of the Upper Urinary Tract: Report of 4 Cases
}

\author{
Lamine Niang1, Charles Kouka ${ }^{2}$, Yoro Diallo ${ }^{2 *}$, Médina Ndoye ${ }^{1}$, Racine Kane ${ }^{1}$, \\ Mohamed Jalloh', Abdoulaye Ndiaye ${ }^{1}$, Issa Labou', Jeanne Diaw ${ }^{1}$, Sérigne M. Gueye ${ }^{1}$ \\ ${ }^{1}$ General Hospital of Grand Yoff, Dakar University, Dakar, Senegal \\ ${ }^{2}$ Health UFR, Thies, Senegal \\ Email: *yorodiallo@hotmail.com
}

Received 6 May 2014; revised 7 June 2014; accepted 9 July 2014

Copyright (C) 2014 by authors and Scientific Research Publishing Inc.

This work is licensed under the Creative Commons Attribution International License (CC BY).

http://creativecommons.org/licenses/by/4.0/

(c) (i) Open Access

\begin{abstract}
Primary tumors of the upper urinary tract are rarely reported in the literature. We thus report here four cases of primary tumors of the upper urinary tract that were difficult to diagnose, in three women and one man. Preoperative diagnosis was established in only two cases requiring a nephro-ureterectomy. The other two cases were surprisingly diagnosed during anatomopathological examination. Preoperative diagnosis was a pyonephrosis in one case and a renal failure resulting from stenosis of the pelvic ureter in the other. Despite modern methods, primary tumors of the upper urinary tract remain difficult to diagnose.
\end{abstract}

\section{Keywords}

Upper Urinary Tract, Primary Tumors, Nephro-Ureterectomy

\section{Introduction}

Primary tumors of the upper urinary tract are rarely reported in the literature. The diagnosis in certain cases is an surgical surprise. We thus report here four cases of primary tumors of the upper urinary tract.

\section{Case Reports}

\subsection{Case \#1}

Mrs H.R.F., 75 years old and without any particular medical history, was hospitalized in May 2009 for a total hematuria of average abundance. Physical examination revealed a relatively good overall health, with moderately stained mucous membranes. The blood count showed a hypochromic microcytic anemia but renal function was

${ }^{*}$ Corresponding author.

How to cite this paper: Niang, L., Kouka, C., Diallo, Y., Ndoye, M., Kane, R., Jalloh, M., Ndiaye, A., Labou, I., Diaw, J. and Gueye, S.M. (2014) Primary Tumors of the Upper Urinary Tract: Report of 4 Cases. Open Journal of Urology, 4, 115-120. 
normal. The urine culture suggested a urinary tract infection to Acinetobacter baumanii sensitive to Colistin and the ultrasound showed that the pelvicalyceal cavities were dilated. A computed tomography (CT) scan was performed and revealed that the right kidney was enlarged, and dilated cavities with heterogeneous content and a tissue-dense pelvic mass were observed, while the other kidney was normal (Figure 1, Figure 2). Cystoscopy indicated that the right ureteral meatus with a normal bladder mucosa was bleeding. Ureteroscopy was difficult to achieve because of the bleeding. A pelvic tumor was diagnosed and treated with nephro-ureterectomy and excision of a bladder flange. The macroscopic aspect was in concordance with morphological data, revealing a pyelocaliceal and ureter tumor. The postoperative course was uneventful. Histological analysis indicated that it was a low-grade papillary carcinoma of the urinary tract (PT1G1 stage). Postoperative exams (ultrasound and cystoscopy) at 6 months were normal. Creatinin levels one year post-surgery were normal.

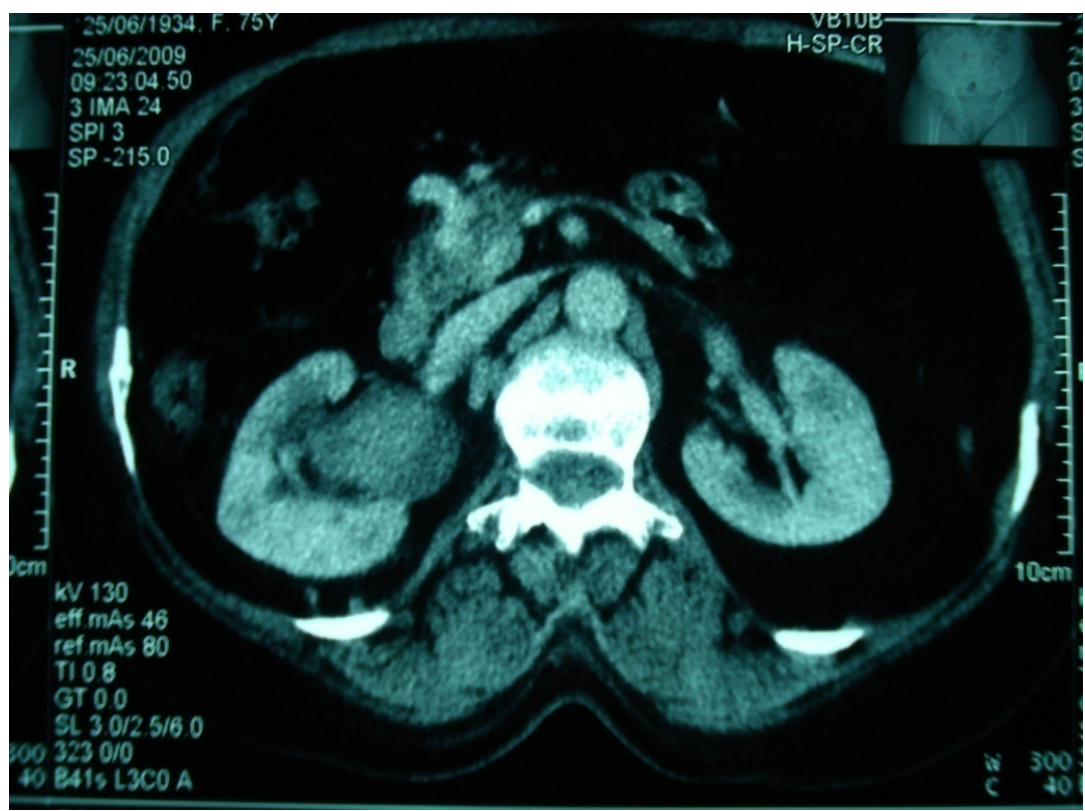

Figure 1. Left pelvic tumor on auro-CT scan without injection.

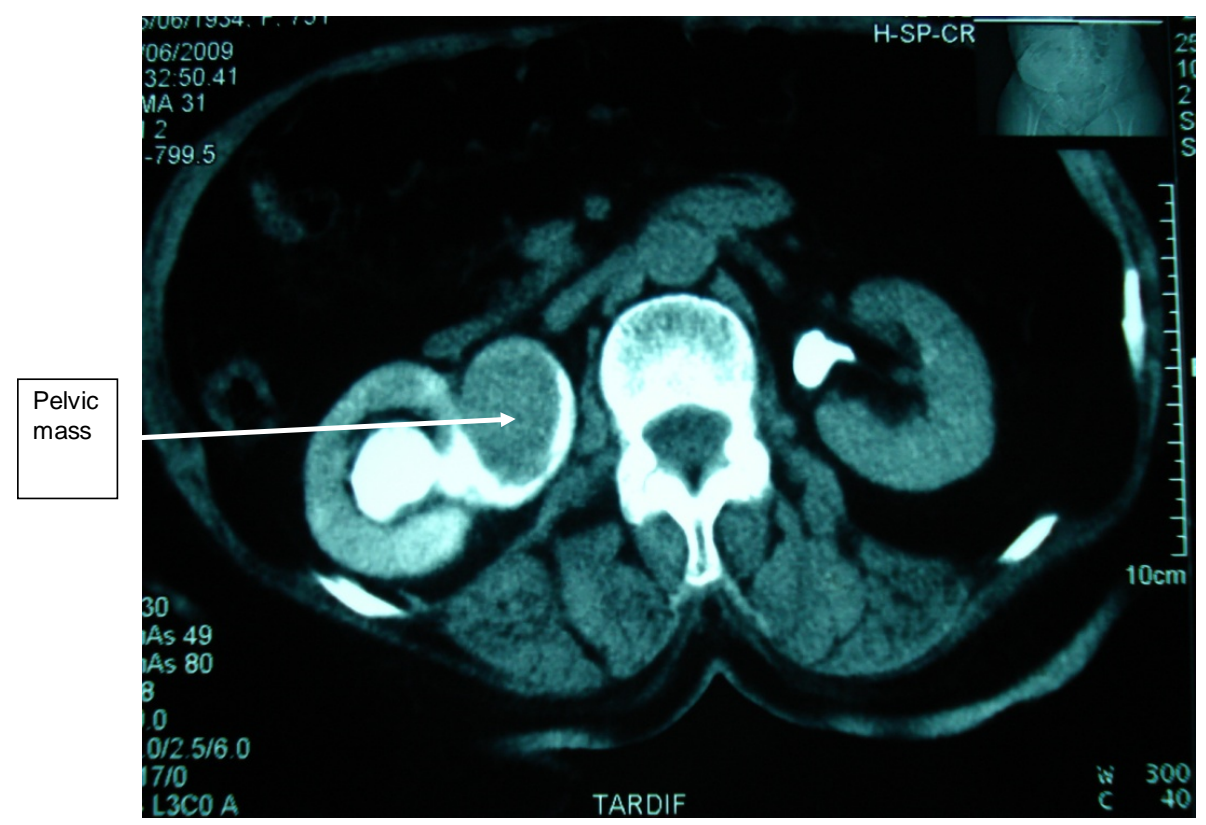

Figure 2. Right pelvic tumor after injection of a contrast agent. 


\subsection{Case \#2}

Mrs H.B., 30 years old, with a history of pain in the left iliac fossa, visited for a left renal colic crisis. Physical examination revealed an agitated patient in a good general condition, with normal coloration of the mucous membranes and left iliac fossa sensitivity. Renal function was normal. X-ray of the abdomen without preparation (AWP) didn't show anything particular. The ultrasound revealed dilated pelvic caliceal cavities in the left kidney. Intravenous urography showed a left ureterohydronephrosis on an obstacle of the left lumbar ureter (Figure 3). The CT scan confirmed a pyelocaliceal and ureteral left dilatation without lithiasis hindrance. The ureteroscopy revealed a stenosing iliac ureter sprouting tumor and biopsy could not be performed because of lack of suitable clamps. An urothelial tumor of the iliac ureter was diagnosed. A nephro-ureterectomy was performed with resection of a bladder flange. Histological examination concluded to a papillary carcinoma (PT1G2) of the left ureter with a discrete interstitial tubulonephritis. Follow-up biological and radiological examinations at 6 months and two years were normal.

\subsection{Case \#3}

Mr. M.N., 47 years old, with a long history of left lower back pain relieved by usual analgesics, was hospitalized in emergency for lumbago, hematuria, fever at $39^{\circ} \mathrm{C}$ and altered general condition. Physical examination revealed hematic urines and a right lumbar fossa sensitivity. Biological and bacteriological laboratory exams revealed a hyperleukocytosis and a Klebsiellapneumoniae infection in urine cultures. The ultrasound showed that the right kidney was enlarged, with highly dilated cavities and heterogeneous content. The CT scan showed an enlarged right kidney, cavities with heterogeneous content (pyonephrosis) and a significant dilatation of the left pyelocaliceal (Figure 4). Right pyonephrosis was diagnosed and a left ureteropelvic junction syndrome was also suggested. Treatment included a left nephrostomy and a right nephrectomy. The macroscopic aspect was in concordance with morphological data, revealing a pyonephrotic kidney and a right pyelocaliceal tumor. The postoperative course was marked by a parietal suppuration on the third day. Histological analysis of the resected specimen indicated that it was a low-grade papillary carcinoma of the urinary tract (PT3G1 stage). Postoperative follow-up showed a recurrence two months later on the remaining ureteral stump by ultrasound, as well as celiac lymph nodes, and spleen and liver metastases. Chest X-ray also revealed lung metastases (Figure 5). The patient died two months after surgery.

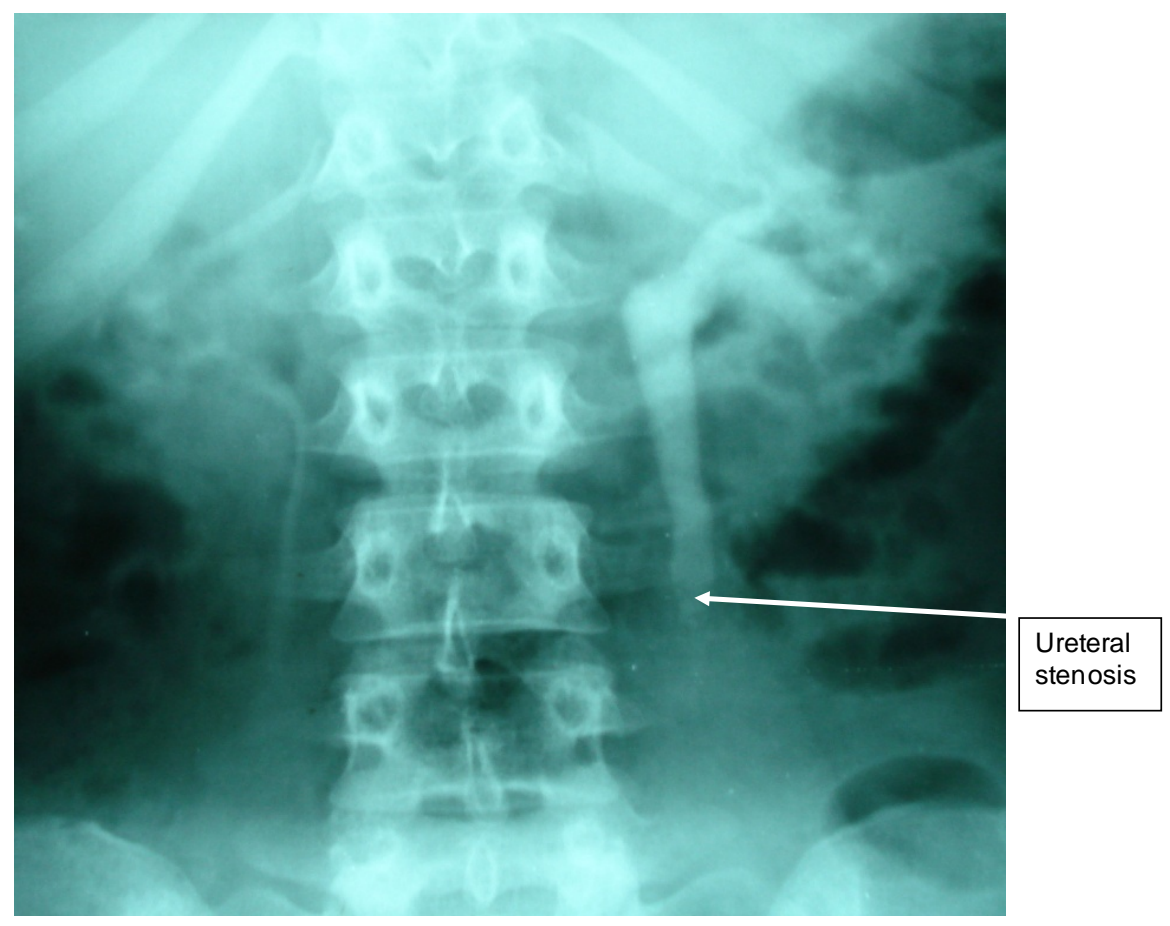

Figure 3. Left neoplastic uretero-hydronephrosis of the iliac ureter. 


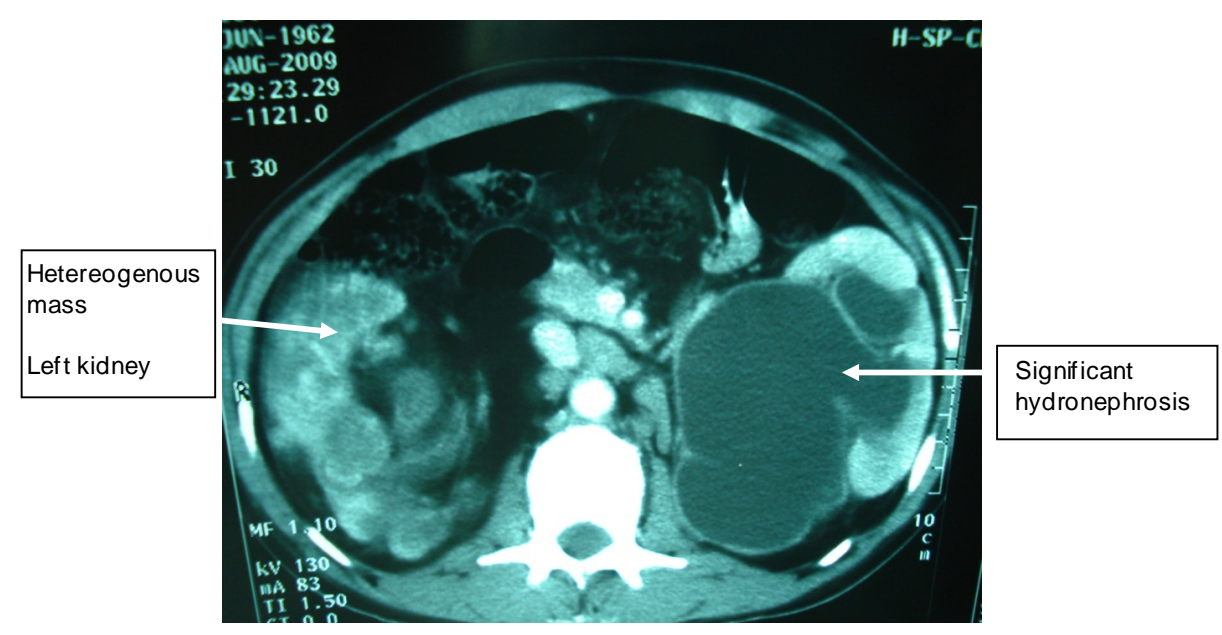

Figure 4. Heterogeneous mass on the right kidney and right hydronephrosis.

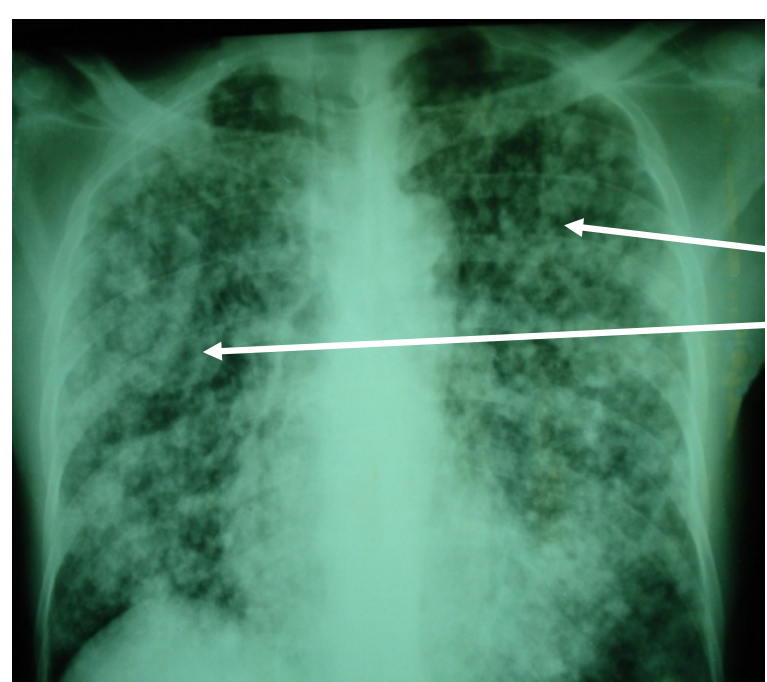

Lung metastases of a pelvic tumor

Figure 5. Lymphangitiscarcinomatosis (TVES (tumeursdes voies excrétrices supérieures) metastases).

\subsection{Case \#4}

Mrs. A.M.F., 63 years old, diabetic under glucophage and with a history of C-section, visited our department because of a total intermittent hematuria and a right renal colic for over four years. Physical examination revealed a pfannestiel-type incision scar and an upper and middle ureteral right points sensitivity. Renal function was normal. The ultrasound showed a right uretero-hydronephrosis on a right pre-ostial obstacle. The uro-CT scan showed a retroperitoneal heterogeneous tissue-dense mass with a right uretero-hydronephrosis. The uro-MRI revealed an aspect of pre-ostialendo-luminal obstacle of the right urinary tract (Figure 6). The laparoscopy revealed a right retroperitoneal mass. Intra-abdominal organs were normal. The patient underwent a nephro-ureterectomy without resection of the peri-meatal bladder cuff. The pathological anatomy concluded to a PT1 grade 3 urothelial carcinoma. Follow-up cytoscopy at 6 months revealed a recurrence on the right peri-meatal bladder of $1 \mathrm{~cm}$ and on the dome of $2 \mathrm{~cm}$. Endoscopic resection of the bladder was performed, without endo-bladder instillation.

\section{Discussions}

Upper urinary tract tumors diagnosis is not always easy. Ten percent of cases are diagnosed accidentally [1]. The most common symptom of these tumors is macroscopic hematuria. Indeed, Djokic et al. showed that 


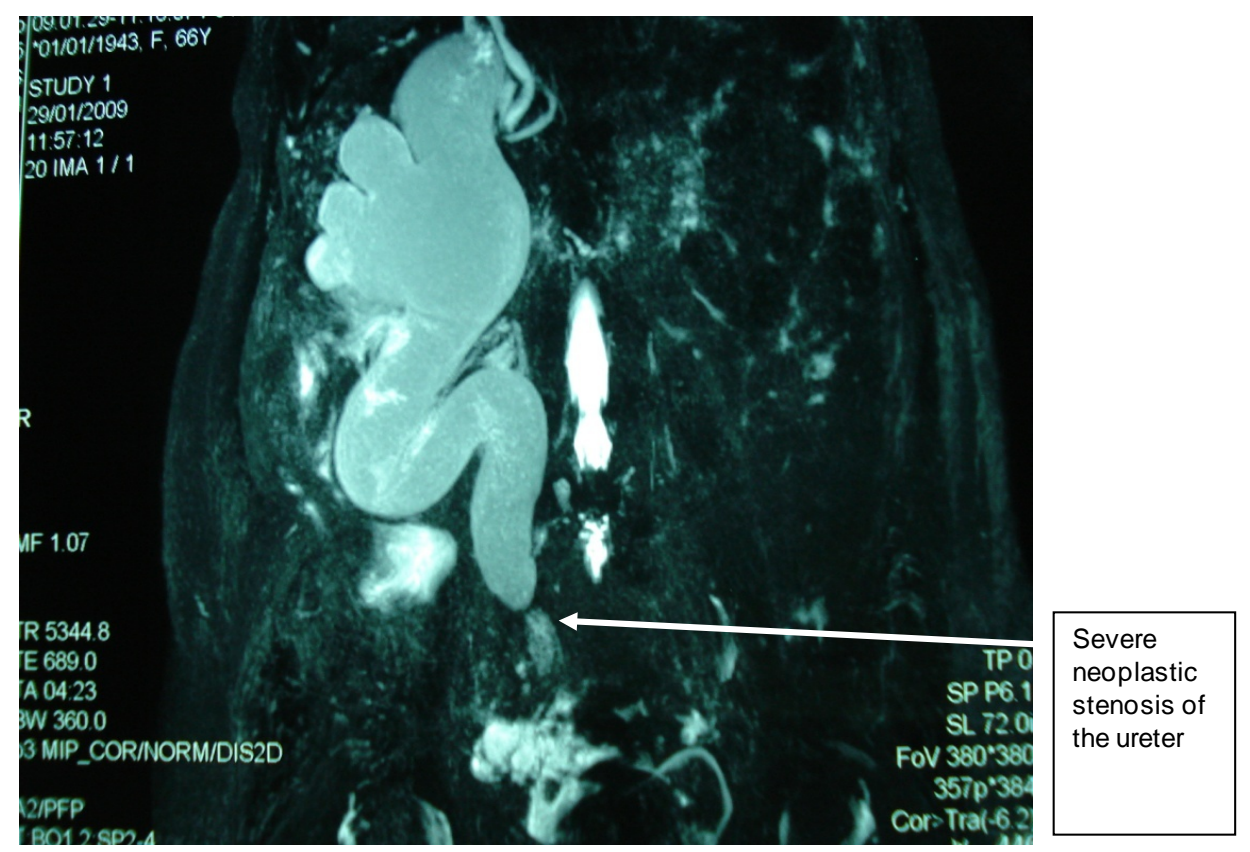

Figure 6. Neoplastic stenosis of the pelvic ureter with upstream dilatation.

macroscopic hematuria was the principal factor revealing the presence of the disease in $83 \%$ of cases [2]. The combination pelvic tumor and pyonephrosis is rare [3]. In our case, preoperative diagnosis was that of a pyonephrosis with ureteropelvic junction syndrome and diagnosis of an upper urinary tract tumor was accidental during anatomopathological examination. The diagnosis of this disease is rarely preoperative.

Bretheaud et al. suggested that pre-operative diagnosis of the tumor was possible on reworked, destroyed, and dilated with purulent content kidneys [4]. The abdominal CT scan affirmed the presence of a tissue-dense mass of 25 to 45 Hounsfield units (HU), increasing slightly after injection of a contrast agent [4]. The intravenous urography, associated or not with the UPR (uretero-pyelography-rétrograde), showed a sensitivity between 50 and 70\%, depending on the series [5] [6]. According to Elliott, sensitivity to these two exams is higher when considering pelvis or calyces lesions [6]. The uro-CT scan is the gold standard for exploring the upper urinary tract and now replaces intravenous urography [7]. The uro-MRI shows a sensitivity near $100 \%$ for the topographic diagnosis of urinary tract obstruction, which is not reduced in case of decreased renal function. The spatial resolution of urothelial lesions for the identification of tumors is variable depending on the series [8].

The sensitivity of rigid ureteroscopy for the diagnosis of ureteral tumors varies depending on the series [9]. Rigid ureteroscopy presents the main disadvantage of not correctly exploring the pelvis and or calyces. The sensitivity and specificity of flexible ureteroscopy increased in recent years with the development of flexible mini-endoscopes [10]. One the main advantages of these new flexible endoscopes is the possibility to explore the overall urinary tract, associated with a therapeutic option. Cytology presents a high specificity but a low sensitivity.

The main treatment is nephro-ureterectomy [10]. In some cases, conservative treatment is indicated. Currently, low-grade or single kidney tumors can be treated with endoscopy, in order to preserve the renal function [11]-[13].

\section{Conclusion}

Upper urinary tract tumors diagnosis is not always easy, and it is this recommended using all diagnosis means available, because a misdiagnosis can be fatal in some cases.

\section{References}

[1] Oosterlinck, W., Solsona, E., van der Meijden, A.P., Sylvester, R., Bohle, A., Rintala, E., et al. (2004) EAU Guidelines on Diagnosis and Treatment of Upper Urinary Tract Transitional Cell Carcinoma. European Urology, 46, 147-154. 
http://dx.doi.org/10.1016/j.eururo.2004.04.011

[2] Djokic, M., Hadzi-Djokic, J., Nikolic, J., Dragicevic, D., Durutovic, O. and Radivojevic, D. (2001) Tumeurs de la voie excrétrice supérieure: Résultats de la chirurgie conservatrice. Progrès en Urologie, 11, 1231-1238.

[3] Fekak, H., Rabii, R., Moufid, K., Joual, A., Dahami, Z. and El Mrini, M. (2002) Tumeurs pyéliques à révélation inhabituelle: A propos de 2 cas. Progrès en Urologie, 12, 482-485.

[4] Bretheau, D., Lechevallier, E. and Uzan, E. (1994) Valeur des examens radiologiques dans le diagnostic et la stadification des tumeurs de la voie excrétrice urinaire supérieure. Progrès en Urologie, 4, 966-973.

[5] Chen, G.L., El-Gabry, E.A. and Bagley, D.H. (2000) Surveillance of Upper Urinary Tract Transitional Cell Carcinoma: The Role of Ureteroscopy, Retrograde Pyelography, Cytology and Urinalysis. The Journal of Urology, 164, 1901-1904. http://dx.doi.org/10.1016/S0022-5347(05)66913-3

[6] Elliott, D.S., Segura, J.W., Lightner, D., Patterson, D.E. and Blute, M.L. (2001) Is Nephroureterectomy Necessary in All Cases of Upper Tract Transitional Cell Carcinoma? Long Term Results of Conservative Endourologic Management of Upper Tract Transitional Cell Carcinoma in Individuals with a Normal Contralateral Kidney. Urology, 58, 174-178. http://dx.doi.org/10.1016/S0090-4295(01)01109-8

[7] Sadow, C.A., Silverman, S.G., O’Leary, M.P. and Signorovitch, J.E. (2008) Bladder Cancer Detection with CT Urography in an Academic Medical Center. Radiology, 249, 195-202. http://dx.doi.org/10.1148/radiol.2491071860

[8] McKenney, J.K., Amin, M.B. and Young, R.H. (2003) Urothelial (Transitional Cell) Papilloma of the Urinary Bladder: A Clinicopathologic Study of 26 Cases. Modern Pathology, 16, 623-629. http://dx.doi.org/10.1097/01.MP.0000073973.74228.1E

[9] Stiborová, M., Frei, E., Sopko, B., Wiessler, M. and Schmeiser, H.H. (2002) Carcinogenic Aristolochic Acids upon Activation by DT-Diaphorase form Adducts Found in DNA of Patients with Chinese Herbs Nephropathy. Carcinogenesis, 23, 617-625. http://dx.doi.org/10.1093/carcin/23.4.617

[10] Bagley, D.H. and Rivas, D. (1990) Upper Urinary Tract Filling Defects: Flexible Ureteroscopic Diagnosis. The Journal of Urology, 143, 1196-2000.

[11] Jemal, A., Siegel, R., Ward, E., Hao, Y., Xu, J. and Thun, M.J. (2009) Cancer Statistics 2009. CA: A Cancer Journal for Clinicians, 59, 225-249. http://dx.doi.org/10.3322/caac.20006

[12] Margulis, V., Shariat, S.F., Matin, S.F., Kamat, A.M., Zigeuner, R., Kikuchi, E., et al. (2009) Outcomes of Radical Nephroureterectomy: A Series from the Upper Tract Urothelial Carcinoma Collaboration. Cancer, 115, 1224-1233. http://dx.doi.org/10.1002/cncr.24135

[13] Thompson, R.H., Krambeck, A.E., Lohse, C.M., Elliott, D.S., Patterson, D.E. and Blute, M.L. (2008) Endoscopic Management for Upper Tract Transitional Cell Carcinoma in Patients with Normal Contralateral Kidneys. Urology, 71, 713-717. http://dx.doi.org/10.1016/j.urology.2007.11.018 
Scientific Research Publishing (SCIRP) is one of the largest Open Access journal publishers. It is currently publishing more than 200 open access, online, peer-reviewed journals covering a wide range of academic disciplines. SCIRP serves the worldwide academic communities and contributes to the progress and application of science with its publication.

Other selected journals from SCIRP are listed as below. Submit your manuscript to us via either submit@scirp.org or Online Submission Portal.
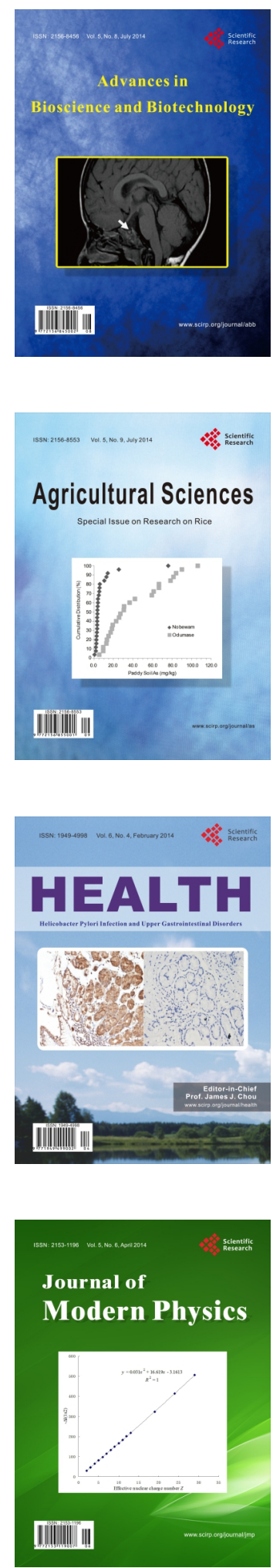
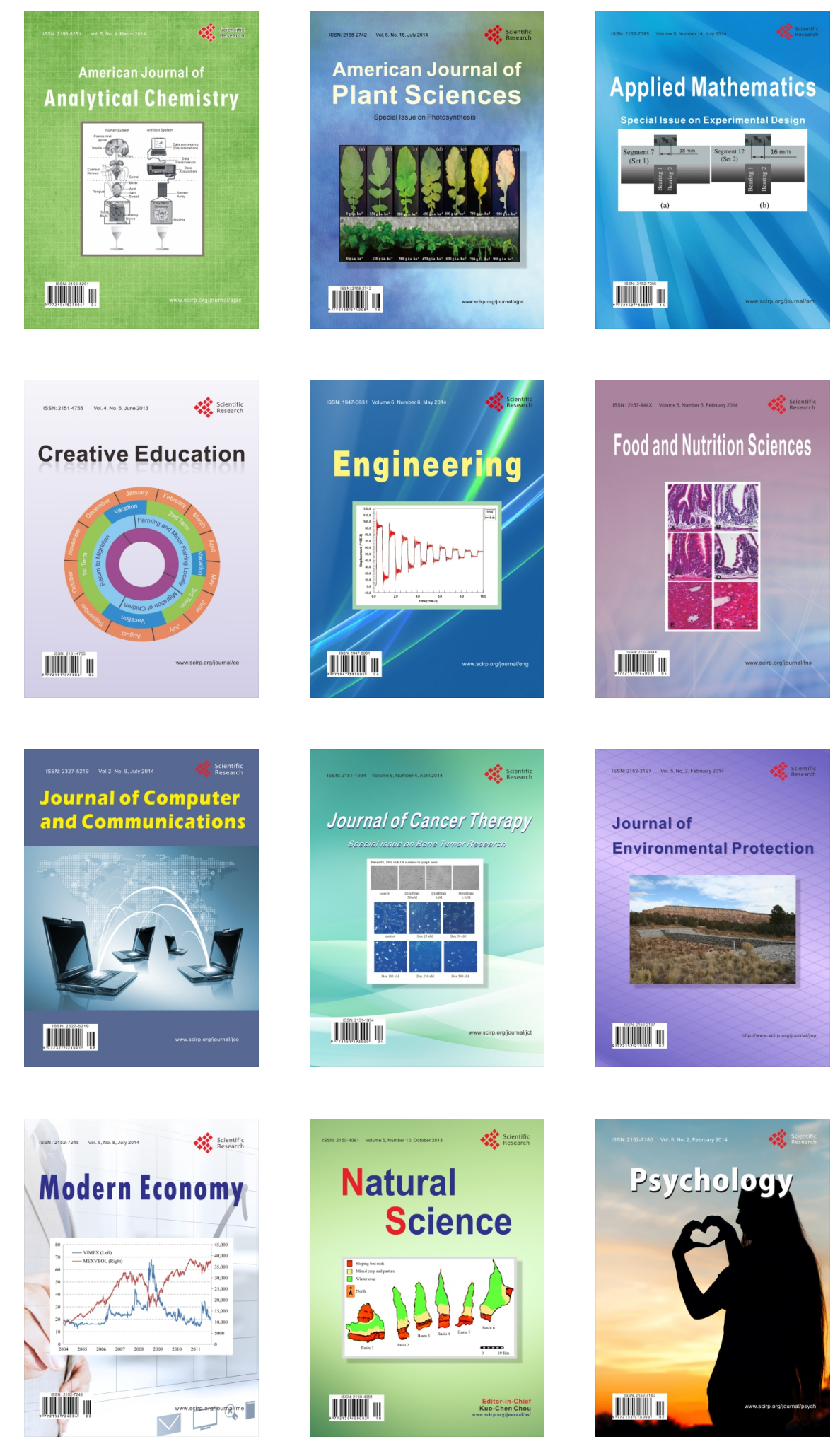